\title{
Electroencephalography in eating disorders
}

This article was published in the following Dove Press journal:

Neuropsychiatric Disease and Treatment

23 December 201I

Number of times this article has been viewed

\section{Ignacio Jáuregui-Lobera ${ }^{1,2}$}

'Behavioral Sciences Institute, ${ }^{2}$ Pablo de Olavide University, Seville, Spain

Correspondence: Ignacio Jáuregui-Lobera Virgen del Monte 3I, Seville 4I0II, Spain $\mathrm{Tel}+34954280789$

Fax +34954278167

Email ignacio-ja@telefonica.net

\begin{abstract}
Clinical applications of electroencephalography (EEG) are used with different objectives, EEG being a noninvasive and painless procedure. In respect of eating disorders, in the 1950s a new line of study about the neurological bases of anorexia nervosa was started and has since been developed. The purpose of this review is to update the existing literature data on the main findings in respect of EEG in eating disorders by means of a search conducted in PubMed. Despite the fact that weight gain tends to normalize some brain dysfunctions assessed by means of EEG, the specific effect of gaining weight remains controversial. Different studies have reported that cortical dysfunctions can be found in patients with anorexia nervosa even after weight gain, whereas others have reported a normalization of EEG in respect of the initial reduced alpha/ increased beta power in those patients with refeeding. Findings of studies that have analyzed the possible relationship between eating disorders and depression, based on sleep EEG disturbances, do not support the idea of eating disorders as a variant of depression or affective disorders. Some EEG findings are very consistent with previous neuroimaging results on patients with anorexia nervosa, reporting neural disturbances in response to stimuli that are relevant to the pathology (eg, stimuli like food exposure, different emotional situations, or body images).
\end{abstract}

Keywords: electroencephalography, event-related potentials, sleep, depression, refeeding, weight gain

\section{Introduction}

Electroencephalography (EEG) is the recording of electrical activity along the scalp produced by the firing of neurons within the brain, ${ }^{1}$ reflecting the synchronized and desynchronized oscillations of the overall cortical activity in the brain. ${ }^{2}$ Brain patterns form wave shapes that are commonly sinusoidal, and the brain state of the individual may make certain frequencies more dominant. Brain waves have been categorized into four basic groups (delta: $0.5-4 \mathrm{~Hz}$; theta: $4-8 \mathrm{~Hz}$; alpha: $8-13 \mathrm{~Hz}$; beta: $>13 \mathrm{~Hz}$ ). ${ }^{3}$ With regard to the study of cognitive processes, the most useful application of EEG recording is the event-related potentials (ERP) technique. Mental processes (eg, perception, selective attention, language processing) occur in milliseconds; thus, whereas neuroimaging techniques localize regions of activation during mental tasks, some EEG applications can define the time course of these activations. In addition, quantitative EEG can better determine spatial structures and localize areas with brain activity or abnormality. ${ }^{3}$ EEG is an image technique that, among others, is included in the group of so-called electrobiological measurements like electrocardiography, electromyography, and magnetoencephalography. In addition to these measurements, another way to explore the human body is to apply other imaging techniques based on other physical principles. submit your manuscript | www.dovepress.com

Dovepress

http://dx.doi.org// 0.2147/NDT.S27302
Neuropsychiatric Disease and Treatment 2012:8 I-II

(C) 2012 Jáuregui-Lobera, publisher and licensee Dove Medical Press Ltd. This is an Open Access article which permits unrestricted noncommercial use, provided the original work is properly cited. 
Computer tomography, magnetic resonance imaging, functional magnetic resonance imaging, positron emission tomography, and single photon emission computed tomography are the most relevant techniques in this group. ${ }^{3}$ Clinical applications of EEG are used with different objectives (eg, to investigate epilepsy, to investigate sleep disorders, to monitor alertness, in coma or brain death), EEG being a noninvasive and painless procedure. With regard to the study of cognitive processes, the most useful application of EEG recording is the ERP technique. ${ }^{4,5}$ Mental processes (eg, perception, selective attention, language processing) occur in milliseconds; thus, whereas positron emission tomography or magnetic resonance imaging localize regions of activation during mental tasks, ERP can define the time course of these activations. In addition, quantitative EEG can better determine spatial structures and localize areas with brain activity or abnormality. ${ }^{3}$ ERPs are voltage fluctuations that are associated in time with some physical or mental occurrence. These can be recorded from the human scalp and extracted from the ongoing EEG by means of filtering and signal averaging. ${ }^{5}$

In the field of eating disorders, articles by Goor ${ }^{6}$ (1954) and $\operatorname{Martin}^{7}$ (1955) started a new line of study about neurological bases of anorexia nervosa. Nevertheless, in 1973, the Royal College of Physicians (London, UK) held a clinicopathological conference on a case of anorexia nervosa and, during the course of the conference, some attendants realized that in the case report there were no EEG data and they asked for them. ${ }^{8}$ It was mainly in the 1980 s when a series of studies was developed applying EEG to eating disorders.

The purpose of this review is to update the existing data on the main findings in respect of EEG in eating disorders.

\section{Methods}

The current review was conducted by means of a search of PubMed. The following search terms were used: "EEG and eating disorders," "neurophysiology and eating disorders," "quantitative EEG and eating disorders," "event-related potentials and eating disorders," "polysomnography and eating disorders," "electro-occulogram and eating disorders," "haptic exploration tasks and eating disorders," and "contingent negative variation and eating disorders." As a result, a total of 309 articles were obtained, excluding all of those that were not specifically focused on anorexia and/or bulimia nervosa, sleeprelated eating disorders, or binge eating (BE). In respect of case reports, due to the shortage of articles specifically focused on these disorders, one related to the first mention of EEG in the literature on eating disorders was considered, as well as two case reports based on sleep-related eating disorders.

\section{Results Sleep and eating disorders}

Initial studies were based on the fact that insomnia, especially early morning waking, is a confirmed feature of anorexia nervosa. In continuous EEG recordings of patients with anorexia nervosa, an increase of the total time asleep per night (light sleep, medium sleep, deep sleep, very deep sleep, and rapid eye movement [REM] sleep) was found following treatment, leading to the conclusion that changes in sleep are more closely associated with disturbances and changes in nutritional status than with disturbances and changes in emotional state. ${ }^{9}$ By means of electro-occulogram recordings (measurements of the amplitude of the standing potential and light response), EEG, and electromyography, it was found that during refeeding, with overall weight gain, there was a significant increase in total length of sleep, as well as REM sleep, the latter increasing especially during the final stages of this process of gaining weight. ${ }^{10}$ In addition, it has been confirmed that low-weight patients usually sleep less and are more restless, especially in the last 4 hours of the night. ${ }^{11}$ After weight gain, a significant increase in length of sleep and REM sleep was observed. As a result, authors have stated that the relationship between insomnia and low body weight might also hold for a variety of psychiatric and other disorders in which there is impaired nutritional status and weight loss. ${ }^{11}$ Comparing patients with anorexia nervosa and bulimia nervosa with normal-weight women, Walsh et $\mathrm{al}^{12}$ found that patients with anorexia nervosa spent less time asleep and less of that time in stage 1 sleep. Moreover, the sleep of the normal-weight patients with bulimia nervosa was clearly similar to that of the controls.

Patients with bulimia nervosa are not easily distinguishable from healthy controls in terms of sleep patterns, whereas patients with anorexia nervosa show some disturbances in sleep efficiency and sleep architecture. ${ }^{13}$ By analyzing arousal and the cyclic alternating sleep pattern, it has been confirmed that altered sleep in eating disorder patients may be related to body mass index, ${ }^{13}$ although this association is controversial. ${ }^{14}$ In respect of sleep architecture, patients with anorexia nervosa seem to have an increase of wakefulness after having got to sleep (due to an increased number of nighttime awakenings), a higher number of arousals, and a reduction in slow-wave sleep and slow-wave activity (SWA) during total sleep time. No relationship between the reduction of SWA and duration of illness has been found, whereas a relationship between a decrease in SWA and body mass index has been reported. Considering the first non-REM sleep cycle, there were no differences between patients with anorexia nervosa and healthy controls. ${ }^{15}$ 
It has been reported that sleep EEG in adolescents with anorexia shows an increased number of awakenings and wakefulness over the rest of the sleeping period, a reduction of sleep efficiency and slow-wave sleep, and a significant reduction in the power spectral values of SWA in all nonrapid eye movement (NREM)-REM cycles of sleep and in undisturbed and stable stage- 4 sleep. ${ }^{16}$ When compared with healthy controls, patients with anorexia nervosa were characterized by a concentration of SWA in the first NREM-REM cycle with decay in the second part of the night. Again, a positive correlation between body mass index and the amount of SWA has been found. ${ }^{16}$ Table 1 shows some studies on sleep EEG and eating disorders.

Besides sleep EEG recordings, recent research based on quantitative EEG has reported greater amplitude of alpha-1 sources $(8-9 \mathrm{~Hz})$ in central, parietal, occipital, and limbic areas of healthy controls when compared with patients with anorexia and bulimia nervosa. ${ }^{17}$ Alpha-2 sources $(10-12 \mathrm{~Hz})$ in parietal, occipital, and limbic areas have shown greater amplitude in controls than in patients with anorexia and bulimia nervosa. Alpha-1 sources in the temporal area showed greater amplitude in controls when compared with patients with anorexia and bulimia nervosa as well as in patients with bulimia nervosa compared with patients with anorexia nervosa. Central alpha-1 source correlated significantly with body mass index in patients. ${ }^{17}$

\section{Sleep, eating disorders, and depression}

Studies based on sleep have suggested neurobiological similarities between patients with eating disorders and those with depression. ${ }^{14,18-21}$ In a study comparing eating disorder patients (without depression) and healthy controls, no significant REM differences were found between the two groups. In addition, low-weight patients with anorexia nervosa appeared to have less delta sleep than controls. In conclusion, authors reported that these findings did not support the idea of eating disorders as a variant of affective disorders. ${ }^{18}$ By means of EEG and a cholinergic REM sleep induction test, no differences were found in sleep patterns among patients with anorexia nervosa and those with bulimia nervosa and healthy controls. Moreover, the induction test results were similar in eating disorder patients and in controls but differed from those reported in depressive patients. ${ }^{19}$ Based on these findings, a posterior study confirmed that, whereas baseline EEG sleep did not differ significantly among eating disorder patients, young depressive patients, and healthy controls, the REM sleep-inducing effect of a cholinergic agent was distinguished in depressive patients, eating disorder patients, and controls. ${ }^{20}$ In respect of the cholinergic REM sleep induction, a significantly faster induction of REM sleep was found in depressive patients when compared with eating disorder patients and controls. Lauer et al have stated that these findings indicate a subthreshold hypersensitivity of the REM sleep-triggering cholinergic transmitter system in depressive patients but not in eating disorder patients. ${ }^{21}$ Eating disorder patients differ from depressive patients in that they have a greater number of, and longer, awakenings. Compared with controls, eating disorder patients show less sleep efficiency, longer awakenings, and less REM sleep. Moreover, patients with a bulimic subtype of anorexia nervosa show an increase in stage 3 sleep. Again, the results do not support a direct association between eating disorders and affective disorders. ${ }^{14}$

Data based on sleep EEG as well as on studies on the similarity between eating disorders and depression seem

Table I Studies on sleep electroencephalography and eating disorders

\begin{tabular}{|c|c|c|c|c|}
\hline Authors & Year & Sample & Technique & Results \\
\hline Crisp et $\mathrm{al}^{9}$ & 1971 & I0 AN women & Sleep EEG & Total time asleep/night increases with treatment \\
\hline Lacey et $\mathrm{al}^{10,11}$ & 1975,1976 & I0 AN (I man, 9 women) & EOG, EEG, EMG & Increase of sleep and REM sleep during refeeding \\
\hline Walsh et $\mathrm{al}^{12}$ & 1985 & $\begin{array}{l}8 \mathrm{AN}, 16 \mathrm{BN} \text { (normal weight), } \\
14 \text { control (normal weight) - all women }\end{array}$ & Sleep EEG & $\begin{array}{l}\text { Patients with AN spent less time asleep and less } \\
\text { time in stage I sleep than patients with } \mathrm{BN} \text { and } \\
\text { normal controls }\end{array}$ \\
\hline Delvenne et $\mathrm{al}^{14}$ & 1992 & $\begin{array}{l}\text { II AN women, I I depressed, } \\
\text { II healthy patients }\end{array}$ & Sleep EEG & $\begin{array}{l}\text { Patients with AN showed less sleep efficiency, } \\
\text { longer awakenings, and less REM sleep. Patients } \\
\text { with AN-purging had an increase in stage } 3 \text { sleep }\end{array}$ \\
\hline Nobili et al ${ }^{16}$ & 1999 & I0 AN women, 10 matched controls & Sleep EEG & $\begin{array}{l}\text { Patients with AN showed an increase of wakefulness } \\
\text { after sleep onset, and a reduction of SWS }\end{array}$ \\
\hline Nobili et $\mathrm{al}^{15}$ & 2004 & 20 AN women, 12 matched controls & Polysomnography & $\begin{array}{l}\text { Patients with AN showed an increase of } \\
\text { wakefulness after sleep onset, a higher number } \\
\text { of arousals, and a reduction of SWS and SWA } \\
\text { during total sleep time }\end{array}$ \\
\hline
\end{tabular}

Abbreviations: AN, anorexia nervosa; BN, bulimia nervosa; EEG, electroencephalography; EOG, electrooculogram; EMG, electroencephalography; REM, rapid eye movement; SWA, slow-wave activity; SWS, slow-wave sleep. 
to suggest the influence of weight on sleep EEG, and the findings do not support that similarity.

\section{Impact of refeeding and weight gain}

The relationship between nutritional status and EEG findings has been reported in several studies, ${ }^{9-11,13,16}$ despite others not finding that relationship. ${ }^{14}$ The debate highlights whether the reported EEG abnormalities are an effect of structural brain changes related to starvation or are predisposing disease markers of anorexia nervosa. ${ }^{22}$ In general, findings have been inconsistent; thus, the association between EEG abnormalities, body mass index, and duration of illness remains uncertain. ${ }^{17,23,24}$

In a study with adolescents with anorexia nervosa and emotionally disturbed patients by means of ERP (auditory), it was found that patients with anorexia nervosa might have difficulty in modulating auditory stimuli adequately at the subcortical level, even after gaining weight. Nevertheless, at the cortical level, the modulation did not differ from controls. At low weight, patients with anorexia nervosa showed a systematic dissociation of the auditory evoked potential amplitude response between cortical and subcortical levels. After weight gain, patients had less dissociation, which was not seen in controls. Authors concluded that to reach regular modulation of sensory information, patients should gain normal weight. ${ }^{25}$

Another study, by means of ERP, reported that body mass index in patients with anorexia nervosa significantly predicted N4 (a negative component occurring 400-600 ms after an incongruent unprimed word among contextually related primed words) amplitudes for a verbal task in the left hemisphere and P3 (P3 or P300 is a positive peak 300-600 ms after a stimulus) amplitudes for a nonverbal task in the right hemisphere. ${ }^{26}$ At follow-up, patients with anorexia nervosa showed longer P3 amplitudes for the verbal task compared with the nonverbal task. The authors stated that these findings are evidence for localized brain dysfunction in anorexia nervosa that only partially normalizes with weight gain.

Highlighting the aforementioned controversy, the possible deficits in haptic exploration tasks (tasks based on the haptic recognition of objects, having stated that the information about the structure of the object may be stored in a similar way by the visual and haptic systems) have been explored before and after weight gain. The comparison of the theta power between controls and patients with anorexia nervosa during haptic exploration tasks showed major differences in both $T_{0}$ and $T_{1}$. Theta power was lower in patients with anorexia nervosa than in controls over the right hemisphere and right parietal regions. It seemed that theta power changes indicated a cortical dysfunction and deficits in somatosensory integration processing of the right parietal cortex in patients with anorexia nervosa even after weight gain. ${ }^{27,28}$ At rest, a theta asymmetry has been observed in patients with anorexia nervosa during the acute stage of starvation $\left(\mathrm{T}_{0}\right)$ but not after weight gain $\left(\mathrm{T}_{1}\right)$. The theta asymmetry over central regions has been observed in patients with anorexia nervosa during the acute stage of starvation $\left(\mathrm{T}_{0}\right)$ as well as after weight gain $\left(\mathrm{T}_{1}\right)$ while performing haptic exploration tasks. In healthy controls, no significant theta asymmetry either at rest or during haptic explorations was found. ${ }^{29}$

Resting EEG before and after refeeding in "eyes open," underweight patients with anorexia nervosa has shown reduced relative alpha power and increased beta power in frontal brain regions. A significant increase in alpha power and a decrease in beta and delta power have been observed within participants after refeeding. "Eyes closed" underweight patients with anorexia nervosa had elevated theta power in parietal-occipital regions, which remained after refeeding. ${ }^{30}$

Methodology problems, mainly based on the variability of the samples (age, body mass index, chronicity, medication, experimental tasks, time of EEG testing), could explain the dispute in respect of the relationship between EEG changes/ weight changes. ${ }^{30}$ Nevertheless, the majority of studies have reported a relationship between weight changes and EEG changes. Table 2 shows some relevant analyses about the relationship between EEG changes and weight changes in eating disorders.

\section{Sleep-related eating disorders and night-eating syndrome}

In 1955, Stunkard et $\mathrm{al}^{31}$ reported abnormal nocturnal eating as night eating syndrome (NES), which comprised nocturnal hyperphagia, insomnia, and morning anorexia. Following this, different polysomnographic (polysomnography is a standard tool in sleep medicine for evaluating sleep-related pathophysiology, sleep architecture, and sleep integrity) studies were published ${ }^{32,33}$ and, in 1991, Schenck et al ${ }^{34}$ identified sleep-related eating disorder (SRED). In cases of NES, patients eat in full wakefulness with overeating between dinner and bedtime and/or full awakenings with complete next-day recall. During eating episodes of SRED, patients eat under partial consciousness with limited subsequent recall.

A polysomnographic study of NES patients showed low levels of sleep efficiency, a high number of awakenings, and a strict relationship between nocturnal eating episodes 
Table 2 Studies on electroencephalography, refeeding, and weight gain

\begin{tabular}{|c|c|c|c|c|}
\hline Authors & Year & Sample & Technique & Results \\
\hline $\begin{array}{l}\text { Rothenberger } \\
\text { et } \mathrm{al}^{25}\end{array}$ & 1991 & $\begin{array}{l}39 \text { AN inpatients, } 27 \text { cross-section, } \\
\text { I } 2 \text { longitudinal, } 12 \text { emotionally } \\
\text { disturbed inpatients }\end{array}$ & AEP & $\begin{array}{l}\text { Tendency to normalize modulation of sensory information } \\
\text { after weight gain in AN }\end{array}$ \\
\hline $\begin{array}{l}\text { Bradley } \\
\text { et al }{ }^{26}\end{array}$ & 1997 & $20 \mathrm{AN}, 20$ control women & ERP & $\begin{array}{l}\text { Brain dysfunction in AN only partially normalizes with } \\
\text { weight gain }\end{array}$ \\
\hline $\begin{array}{l}\text { Grunwald } \\
\text { et } \mathrm{al}^{28}\end{array}$ & 2001 & I0 AN women, 10 control women & $\begin{array}{l}\text { EEG during haptic } \\
\text { exploration tasks }\end{array}$ & $\begin{array}{l}\text { Cortical dysfunction and deficits in somatosensory } \\
\text { integration processing of the right parietal cortex in AN } \\
\text { even after weight gain }\end{array}$ \\
\hline $\begin{array}{l}\text { Grunwald } \\
\text { et } \text { al }^{29}\end{array}$ & 2004 & $10 \mathrm{AN}, 10$ healthy controls & $\begin{array}{l}\text { EEG during haptic } \\
\text { exploration tasks }\end{array}$ & $\begin{array}{l}\text { Theta asymmetry over central regions was observed in } \\
\text { AN during starvation as well as after weight gain while } \\
\text { performing the tasks }\end{array}$ \\
\hline Hatch et $\mathrm{al}^{30}$ & 2011 & $\begin{array}{l}37 \text { AN first admission, } 45 \text { controls, } \\
28 \text { AN after refeeding }\end{array}$ & Resting EEG & $\begin{array}{l}\text { "Eyes open" (underweight AN): reduced relative alpha } \\
\text { power and increased beta power in frontal regions. Increase } \\
\text { in alpha and decrease in beta were found when refeeding. } \\
\text { "Eyes closed" (underweight AN): elevated theta in parietal- } \\
\text { occipital regions, which remained after refeeding }\end{array}$ \\
\hline
\end{tabular}

Abbreviations: AN, anorexia nervosa; AEP, auditory event-related potentials; ERP, event-related potentials.

and NREM sleep. The average length of each episode was 3.5 minutes, and the eating latency (interval between awakening and start of chewing) was shorter than 30 seconds in half of the episodes. ${ }^{35}$

In 2006, a videopolysomnographic study conducted by Vetrugno et $\mathrm{al}^{36}$ in a sample of drug-free nocturnal eating patients showed that eating always occurred after complete awakening from NREM sleep (only occurring from REM sleep in one patient), and was characterized by EEG alpha activity with no dissociated features of state-dependent sleep variables. Patients were fully conscious and remembered the events the next day. Recurring chewing and swallowing movements during sleep were associated in half of the events with EEG arousals. This finding (eating during full alertness) is atypical compared with previously reported SRED; thus, the authors questioned whether it was SRED or NES. In addition, in a case report, a SRED with both typical and atypical features has been described.$^{37}$ In this case, the nocturnal eating episodes were considerably higher (20-35 episodes weekly) than an average SRED.

\section{Different stimuli and EEG in eating disorders}

The effect of different stimuli on EEG in eating disorder patients has been studied considering all sensory modalities. ${ }^{38-45,50,51,55}$ Comparing the effect of unpleasant (bitter tea) and pleasant (chocolate) gustatory stimuli by means of multichannel EEG, patients with anorexia nervosa showed lower-dimensional complexity in the majority of recording sites than that seen in healthy controls, independent of taste conditions. Higher omega complexity was seen in controls in the left side, irrespective of taste effects, but no such hemispheric difference was observed in patients with anorexia nervosa. The authors suggested that the lower-dimensional complexity observed in patients with anorexia nervosa might be caused by the long-lasting effects of malnutrition. In addition, it was suggested that the lack of omega complexity change in response to exposure of sweet taste in the left side observed in patients with anorexia nervosa might correspond to a decreased sensitivity to such stimuli in these patients. ${ }^{38}$ Furthermore, it has been reported that patients with anorexia nervosa show a significantly higher percent of theta and a lower percent of alpha-1 band power, irrespective of the type of taste effects and hemispheric side when compared with controls. The pattern of activation was found to be different between the two groups after exposure to sweet (milk chocolate) and bitter (black tea) stimuli. ${ }^{39}$

Brain electrical activity (quantitative EEG) has also been recorded during food presentation in obese BE patients. As a result, $\mathrm{BE}$ patients showed greater frontal beta activity than the non-BE patients in both the eyes closed and the eyes open situations and independently of the stimulus (a picture of a landscape versus a meal). ${ }^{40}$ No differences were found in alpha, delta, or theta amplitudes. It seems that the elevated frontal beta activity might be a marker of the dysfunctional disinhibition-inhibition mechanism, which could make the obese BE patients more vulnerable or sensitive to food and environmental cues. ${ }^{40}$

Because appetitive conditioning is assumed to be altered in eating disorders among other psychopathological conditions, appetitive taste and appetitive taste conditioning have been studied by means of ERP in healthy subjects to 
improve the methodology to study the EEG responses to unconditioned appetitive stimuli. In this regard, a clear P1/ $\mathrm{N} 1 / \mathrm{P} 2$ complex (which provides information regarding the arrival of sound information to the auditory cortex) and a late positive potential (P3) with maxima at right frontocentral electrode sites, in response to the taste stimuli have been reported. Of these components, the P3 in particular has shown great differences between sweet and neutral taste. In addition, the EEG responses to the taste-conditioned stimuli also showed the expected differences for both P2 and P3 at fronto-central electrodes. ${ }^{41}$

In a combined ERP and behavioral study to explore explicit and implicit associations between shape/weight and self-evaluation by means of shape/weight-related prime sentences and congruent/incongruent target words, ERP, reaction times, and subjective ratings were used to assess the affective priming effects. Stronger affective priming effects were found in patients with anorexia and bulimia nervosa compared with in healthy controls. ERP showed affective priming effects only in patients with bulimia nervosa. Eating disorder patients associate shape/weight concerns with the nonappearance-related self-evaluation domains of interpersonal relationships and achievement/performance. These associations seem to be encoded deeper in patients with bulimia nervosa. ${ }^{42}$

Recognition of emotional states is affected in eating disorders, and difficulties in recognizing emotions from facial expression have been reported in patients with anorexia nervosa. ${ }^{43,44}$ Brain signals related to the perception of emotional faces are usually studied by means of ERP. With regard to eating disorders, components like N200 (N200 or N2 is a negative-going wave that peaks $200-350 \mathrm{~ms}$ poststimulus) and P300 mostly used. ${ }^{45}$ The N200 is related to the inhibition of executive functions and is sensitive to associated with processing of unfamiliar stimuli. The P300 is an index of attention and processing capacity. ${ }^{46-49}$ In a recent study by means of visual evoked potentials to emotional faces, patients with anorexia nervosa showed no modulation of emotional face processing and displayed increased N200 amplitudes in response to all emotional categories and decreased those potentials in response to unpleasant emotional faces in the P300 time range when compared with healthy controls. ${ }^{50}$ The authors concluded that differences in brain dynamics might contribute to difficulties in the correct recognition of facially expressed emotions.

As in other areas of this field, findings in respect of recognition of emotional states are controversial to some extent, due to possible effects of malnourishment or low weight. Hatch et $\mathrm{al}^{51}$ have recently reported that patients with anorexia nervosa had a significant alteration in ERP compared with healthy controls. Irrespective of the type of stimulus, early and late ERP components were reduced in patients with anorexia nervosa when underweight and after weight gain, especially in the temporo-occipital regions, suggesting a persistent disruption of the early automatic appraisal of salient emotional signals.

In two recent studies, ${ }^{52,53}$ the oddball paradigm (a technique used in evoked potential research in which trains of stimuli that are usually auditory or visual are used to assess the neural reactions to unpredictable but recognizable events) ${ }^{54}$ has been applied to test the attention cortical responses to enlarged faces and the corresponding relationship with fat/ weight in normal-weight and obese subjects. A relationship between body fat and prefrontal attention processes to body image was found in normal-weight subjects. In addition, anterior-posterior cortical attention processes to face images declined in underweight subjects.

On the basis that central catecholamines, especially dopaminergic and noradrenergic systems, have affected the appetitive behavior in patients with anorexia nervosa, the characteristics of contingent negative variation (a slow negative-going ERP elicited by a warning stimulus that requires anticipation of a target stimulus) and postimperative negative variation (a slow brain potential observable after the onset of an imperative stimulus in a forewarned reaction time task) were studied in children with anorexia nervosa. These children showed diminished amplitude of the contingent negative variation and a significantly more attenuated early and late contingent negative variation amplitude at central midline than normal children. In respect of postimperative negative variation, no differences were found between children with anorexia nervosa and healthy children. It was suggested that early contingent negative variation might be diminished by norepinephrine deficiency and that late contingent negative variation might be attenuated by dopaminergic deficiency in children with anorexia nervosa. Reduced contingent negative variation might represent impaired cognitive processes, which reflect impaired appetitive behavior in children with anorexia nervosa. ${ }^{55}$ Table 3 summarizes the main findings on stimuli presentation and EEG in eating disorders.

\section{Other lines of study}

Other attempts have been developed to explore eating disorders and eating disturbances by means of EEG. Thus, EEG correlates were explored in compulsive eaters, ${ }^{56}$ the typology 
Table 3 Stimuli presentation and electroencephalography in eating disorders

\begin{tabular}{|c|c|c|c|c|}
\hline Authors & Year & Sample & Technique & Results \\
\hline $\begin{array}{l}\text { Tóth } \\
\text { et al }{ }^{38}\end{array}$ & 2004 & $\begin{array}{l}9 \text { patients with AN ( } 7 \text { women), } \\
10 \text { healthy controls }\end{array}$ & $\begin{array}{l}\text { Multichannel EEG, gustatory stimuli - } \\
\text { unpleasant (bitter tea), pleasant } \\
\text { (chocolate) }\end{array}$ & $\begin{array}{l}\text { Patients with AN showed lower-dimensional } \\
\text { complexity than healthy controls. No } \\
\text { hemispheric difference in patients with AN }\end{array}$ \\
\hline $\begin{array}{l}\text { Tóth } \\
\text { et al }{ }^{39}\end{array}$ & 2004 & $\begin{array}{l}9 \text { outpatients with AN } \\
\text { ( } 7 \text { women), } 9 \text { matched controls }\end{array}$ & $\begin{array}{l}\text { EEG, gustatory stimuli - sweet } \\
\text { (milk chocolate), bitter (black tea) }\end{array}$ & $\begin{array}{l}\text { Higher percent of theta and lower percent } \\
\text { of alpha-I in } \mathrm{AN} \text {, irrespective of the type } \\
\text { of taste effects and hemisphere }\end{array}$ \\
\hline $\begin{array}{l}\text { Pollatos } \\
\text { et al }\left.\right|^{50}\end{array}$ & 2008 & $\begin{array}{l}\text { I } 2 \text { AN women, healthy } \\
\text { controls }\end{array}$ & VEP, visual stimuli - emotional faces & $\begin{array}{l}\text { Increased N200 to all emotional categories, } \\
\text { decreased VEP to unpleasant emotional faces } \\
\text { in the P300 time range }\end{array}$ \\
\hline $\begin{array}{l}\text { Hatch } \\
\text { et } \mathrm{al}^{51}\end{array}$ & 2010 & $\begin{array}{l}28 \mathrm{AN} \text { at admission and after } \\
\text { gaining weight, healthy controls }\end{array}$ & $\begin{array}{l}\text { ERP, stimuli - overt and covert } \\
\text { presentation of emotion expressions }\end{array}$ & $\begin{array}{l}\text { Irrespective of stimuli, early and late components } \\
\text { of ERP were reduced in patients with AN } \\
\text { at admission and after weight gain }\end{array}$ \\
\hline $\begin{array}{l}\text { Tammela } \\
\text { et a }\left.\right|^{40}\end{array}$ & 2010 & $\begin{array}{l}\text { Obese women with binge } \\
\text { eating and without binge eating }\end{array}$ & $\begin{array}{l}\text { qEEG, resting state (eyes open/closed), } \\
\text { visual stimuli - landscape, meal }\end{array}$ & $\begin{array}{l}\text { Binge-eating patients showed greater frontal beta } \\
\text { activity (eyes open and eyes closed) }\end{array}$ \\
\hline $\begin{array}{l}\text { Franken } \\
\text { et } \mathrm{a}^{41}\end{array}$ & 2011 & 32 healthy subjects & ERP, taste conditioning task & $\begin{array}{l}\text { A clear } \mathrm{PI} / \mathrm{NI} / \mathrm{P} 2 \text { complex and a late positive } \\
\text { potential }(\mathrm{P} 3) \text { in response to the taste stimuli }\end{array}$ \\
\hline $\begin{array}{l}\text { Blechert } \\
\text { et } \mathrm{al}^{42}\end{array}$ & 2011 & $\begin{array}{l}\text { Patients with } \mathrm{AN} \text { and } \mathrm{BN} \text {, and } \\
\text { healthy controls }\end{array}$ & $\begin{array}{l}\text { ERP, RT, subjective ratings, stimuli - } \\
\text { weight/shape-related prime sentences }\end{array}$ & $\begin{array}{l}\text { Stronger affective priming effects in ED } \\
\text { compared with controls on RT and subjective } \\
\text { ratings. ERP showed affective priming only in BN }\end{array}$ \\
\hline
\end{tabular}

Abbreviations: AN, anorexia nervosa; BN, bulimia nervosa; ED, eating disorders; EEG, electroencephalography; ERP, event-related potentials; qEEG, quantitative EEG; RT, reaction times; VEP, visual-evoked potentials.

of disordered eating behavior was assessed by means of $\mathrm{EEG},{ }^{57}$ a relative right frontal activity was associated with greater self-reported restraint among chronic dieters, ${ }^{58}$ and some attempts have been made to use EEG for prognostic prediction in eating disorders. ${ }^{59}$ Nevertheless, to date, these studies do not seem to have started a clear line of research.

\section{Discussion}

The most recent studies on the relationship between sleep disturbances and eating disorders have usually related these disturbances with neurobiological consequences of the malnutrition state. ${ }^{13,16}$ These consequences are supposed to be reflected as secondary functional and anatomic alterations in the brain..$^{15}$ In addition, results about awake EEG in eating disorders seem to support the view that these disorders are related to altered mechanisms of cortical neural synchronization, especially in Rolandic alpha rhythms. ${ }^{17}$ In respect of sleep EEG in eating disorders, it must be noted that the majority of studies are based on samples comprising only women and mainly patients suffering from anorexia nervosa. Furthermore, the sample sizes are normally small, ranging from ten to 25 patients; EEG recording techniques vary; and rarely are data about medication provided.

Despite the fact that weight gain tends to normalize some brain dysfunctions assessed by means of EEG, the specific effect of gaining weight remains controversial. Different studies have reported that cortical dysfunctions can be found in patients with anorexia nervosa even after weight gain. ${ }^{26,28}$
Others have reported a normalization of EEG in respect of the initial reduced alpha/increased beta power in patients with anorexia nervosa with refeeding. ${ }^{30}$

The reduced alpha/increased beta pattern in anorexia nervosa has usually been reported not only in these patients but also in malnourished children. ${ }^{17,22,61}$ Brain areas of abnormalities in EEG seem to be consistent with some functional deficits found in patients with anorexia nervosa, which are dependent on prefrontal and frontal functioning. ${ }^{62,63}$ These types of functional deficits have also been found by means of neuroimaging in eating disorders. ${ }^{64}$ The aforementioned reduced alpha/increased beta pattern relates to an underweight state in eyes open EEG changes after refeeding (alpha power increases and beta and delta power decreases). Eyes closed underweight patients with anorexia nervosa have elevated theta in parietal-occipital regions, which remains after refeeding. ${ }^{30}$ The complex reduced alpha/increased beta/increased theta has been related to a high level of cortical activation, which usually appears with high levels of anxiety. In this regard, refeeding weight gain and reduction of anxiety might be relevant to normalize EEG. ${ }^{30}$

In general, the controversy about the relationship between eating disorders and EEG disturbances has been difficult to resolve because of the significant variability in the eating disorder samples in terms of age, body mass index, EEG technique used, medications, duration of illness, and experimental settings. ${ }^{30}$ In respect of the relationship 
Table 4 Electroencephalography in eating disorders: main findings

- Sleep EEG of eating disorder patients, mainly in anorexia nervosa, shows almost complete normalization after refeeding.

- In respect of the neurobiological similarities between patients with eating disorders and those with depression, EEG findings do not support that association.

- In respect of the EEG changes/weight changes, there is wide controversy mainly based on methodological problems (eg, age, body mass index, chronicity, medication, experimental tasks, time of EEG testing).

- Some differences between patients with anorexia nervosa and healthy controls in respect of ERP to emotional stimuli have been found, and to some extent those differences remain after weight gain.

- The reduced CNV found in some studies among patients with anorexia nervosa might represent impaired cognitive processes, which reflect impaired appetitive behavior.

- During food presentation, binge-eating obese patients show greater frontal beta activity than nonbinge-eating obese patients in both the eyes closed and eyes open groups, independently of the stimulus.

- It has been reported that alpha-I sources in temporal area show greater amplitude in controls when compared with patients with anorexia and bulimia nervosa as well as in patients with bulimia nervosa compared with patients with anorexia nervosa.

Abbreviations: CNV, contingent negative variation; EEG, electroencephalography; ERP, event-related potentials.

between EEG disturbances and the changes with weight gain, the results are also controversial. It seems that some alterations might persist after gaining weight, whereas some authors have reported complete normalization after refeeding.

With regard to NES and SRED, it must be noted that SRED can be caused, among other things, by nocturnal bulimia nervosa, nocturnal psychogenic dissociative disorder, medical triggers, or cessation of cigarette smoking. ${ }^{60}$ It has therefore been suggested that SRED can be viewed as a final common pathway disorder that can be accessed by a variety of sleep disorders and medications. ${ }^{37}$ Findings of studies that have analyzed the possible relationship between eating disorders and depression, based on sleep EEG disturbances, do not support the idea of eating disorders as a variant of depression or affective disorders. ${ }^{14,18-21}$

Data from emotions-based studies by means of EEG firstly suggest that emotional face recognition involves the amygdala (fear/anger); the insula and basal ganglia (disgust); and the cingulate, medial frontal, and parietal cortices (happiness). ${ }^{65}$ Neuroimaging studies have reported functional abnormalities in prefrontal, cingulated, and temporal areas as a response to different stimuli; ${ }^{64,66}$ thus, the link between neuroimaging data and EEG data may better reflect some dysfunctional patterns. In fact, the observed reduced P300 response to negative emotional faces in patients with anorexia nervosa has been interpreted as possible evidence of decreased cognitive processing ability in respect of negative emotional faces, which could lead to social difficulties and, as a consequence, to the maintenance of eating disorders. ${ }^{50}$ Some ERP findings are very consistent with previous neuroimaging results on patients with anorexia nervosa, reporting neural disturbances in response to stimuli that are relevant to the pathology (eg, stimuli like food exposure, different emotional situations, or body images). ${ }^{51}$

Some of the most recent studies (2004-2011) are those related to the analysis of the response to different stimuli by means of ERP. ${ }^{38-45,50,51}$ Some differences in that response have been found in eating disorder patients versus healthy controls. Those differences are repeatedly reported as varying according to the sensory modality chosen. In this line of study, some differences have been reported between patients with anorexia and bulimia nervosa and between obese patients who do or do not binge.

Finally, the increased theta in parietal-occipital regions may suggest a stable, generalized disturbance of cortical activity, which is most apparent in a resting or relaxed state (eyes closed) and which is not adaptive or functional like the frontal activity but instead is a reflection or marker of underlying anxiety sensitivity/vulnerability that is found to predate anorexia nervosa onset and which persists after recovery. ${ }^{67,68}$

\section{Conclusion}

The aforementioned methodological weaknesses (significant variability in the eating disorder samples for age, body mass index, EEG techniques, medications, duration of illness, experimental settings) maintain the controversy about the relationship between eating disorders and EEG disturbances. However, a reduced alpha/increased beta EEG pattern seems to be related to states of undernutrition, causing functional deficits that have been reported to some extent by means of neuroimaging techniques in eating disorders. Whereas the reduced alpha/increased beta pattern changes with refeeding in eyes closed patients, elevated theta in parietal-occipital regions in underweight patients with anorexia nervosa remains after refeeding. These types of EEG findings are 
usually related not only to underweight but also to a high level of cortical activation.

The studies based on ERP by means of different stimuli permit the detection of functional abnormalities, which also have been observed by means of neuroimaging. Again, complementarity seems to exist between EEG and neuroimaging studies in terms of the study of overall functions, which are the result of an interaction among the different brain areas as well as the connections between them. In fact, eating disorders might reflect some disturbances of a system of interconnecting pathways or circuits in the brain.

Up to date research findings do not seem to be easily implemented in clinical practice. There are no accurate EEG biomarkers to be applied to guide the diagnosis and treatment of eating disorder patients. Above and beyond some changes with refeeding, there are no accurate parameters that could be useful from a clinical point of view.

In future, it seems that, besides neuroimaging, EEG might be a useful tool for the follow-up of patients, to establish what changes could be expected with refeeding or what disturbances remain unchanged despite weight gain. A study of EEG responses to different stimuli (food, emotions, body image) might be another future focus for research. In fact, Tóth et $\mathrm{al}^{39}$ asked whether EEG alterations are caused by changes in arousal or by the affective value of the applied stimuli.

A relevant factor in the development of anorexia nervosa might be a pathological perception of gustatory stimuli. To some extent, earlier research has been based on the study of patients with anorexia or bulimia nervosa. The response to food stimuli and to different emotional states among patients with obesity (especially those with BE disorder) may be another line of study in the future. In fact, there is a field of study based on the relationship between mental imagery and food craving (eg, Tiggeman and Kemps ${ }^{69}$ ), which could be implemented in addition to EEG techniques. Table 4 summarizes the most relevant findings on EEG and eating disorders.

\section{Disclosure}

The author reports no conflicts of interest in this work.

\section{References}

1. Niedermeyer E, Lopes da Silva F. Electroencephalography: Basic Principles, Clinical Applications, and Related Fields. Philadelphia, PA: Lippincot Williams and Wilkins; 2004.

2. Gordon E, Rennie C, Toga A, Mazziatta J. Human brain imaging technologies. In: Gordon E, editor. Integrative Neuroscience. Amsterdam: Harwood Academic Publishers; 2005:233-244.
3. Teplan M. Fundamentals of EEG measurement. Measurement Science Review. 2002;2(2):1-11.

4. Bickford RD. Electroencephalography. In: Adelman G, editor. Encyclopedia of Neuroscience. Cambridge, MA: Birkhauser; 1987: 371-373.

5. Picton TW, Bentin S, Berg P, Donchin E, Hillyard SA, Johnson R Jr, et al. Guidelines for using event-related potentials to study cognition: recording standards and publication criteria. Psychophysiology. 2000; $37: 127-152$.

6. Goor C. EEG in anorexia nervosa. Electroencephalogr Clin Neurophysiol. 1954;6:350.

7. Martin F. Pathological neurological and psychiatric aspects of some deficiency manifestations with digestive and neuro-endocrine disorders. II. Studies of the changes in the central nervous system in two cases of anorexia (so-called anorexia nervosa) in young girls. Helv Med Acta. 1955;22(4-5):522-529.

8. Daly JJ, Nabarro JDN. A case of anorexia. Br Med J. 1973;2:158-163.

9. Crisp AH, Stonehill E, Fenton GW. The relationship between sleep, nutrition and mood: a study of patients with anorexia nervosa. Postgrad Med J. 1971;47(546):207-213.

10. Lacey JH, Crisp AH, Kalucy RS, Hartmann MK, Chien CN. Weight gain and the sleeping electroencephalogram: study of 10 patients with anorexia nervosa. Br Med J. 1975;4(5996):556-568.

11. Lacey JH, Crisp AH, Kalucy RS, Hartmann M, Chien C. Study of EEG sleep characteristics in patients with anorexia nervosa before and after restoration of matched population mean weight consequent on ingestion of a "normal" diet. Postgrad Med J. 1976;52(603):45-49.

12. Walsh BT, Goetz R, Roose SP, Fingeroth S, Glassman AH. EEGmonitored sleep in anorexia nervosa and bulimia. Biol Psychiatry. 1985;20(9):947-956.

13. Della Marca G, Farina B, Mennuni GF, Mazza S, Di Giannantonio M, Spadini V, et al. Microstructure of sleep in eating disorders: preliminary results. Eat Weight Disord. 2004;9(1):77-80.

14. Delvenne V, Kerkhofs M, Appelboom-Fondu J, Lucas F, Mendlewicz J. Sleep polygraphic variables in anorexia nervosa and depression: a comparative study in adolescents. J Affect Disord. 1992;25(3): $167-172$.

15. Nobili L, Baglietto MG, Beelke M, De Carli F, Di Comite R, Fiocchi I, et al. Impairment of the production of delta sleep in anorectic adolescents. Sleep. 2004;27(8):1553-1559.

16. Nobili L, Baglietto MG, De Carli F, Savoini M, Schiavi G, Zanotto E, et al. A quantified analysis of sleep electroencephalography in anorectic adolescents. Biol Psychiatry. 1999;45(6):771-775.

17. Rodriguez G, Babiloni C, Brugnolo A, Del Percio C, Cerro F, Gabrielli F, et al. Cortical sources of awake scalp EEG in eating disorders. Clin Neurophysiol. 2007;118(6):1213-1222.

18. Levy AB, Dixon KN, Schmidt H. REM and delta sleep in anorexia nervosa and bulimia. Psychiatry Res. 1987;20(3):189-197.

19. Lauer C, Zulley J, Krieg JC, Riemann D, Berger M. EEG sleep and the cholinergic REM induction test in anorexic and bulimic patients. Psychiatry Res. 1988;26(2):171-181.

20. Lauer C, Krieg JC, Zulley J, Riemann D, Berger M. Sleep in anorexia nervosa, bulimia nervosa and depressive diseases: a polysomnographic comparative study. Fortschr Neurol Psychiatr. 1989;57(10): 403-410.

21. Lauer CJ, Krieg JC, Riemann D, Zulley J, Berger M. A polysomnographic study in young psychiatric inpatients: major depression, anorexia nervosa, bulimia nervosa. J Affect Disord. 1990;18(4): 235-245.

22. Grebb JA, Yingling CD, Reus VI. Electrophysiologic abnormalities in patients with eating disorders. Compr Psychiatry. 1984;25(2): 216-224.

23. Crisp AH, Fenton GW, Scotton L. A controlled study of the EEG in anorexia nervosa. Br J Psychiatry. 1968;114(514):1149-1160.

24. Neil JF, Merikangas JR, Foster FG, Merikangas KR, Spiker DG, Kupfer DJ. Waking and all-night sleep EEGs in anorexia nervosa. Clin Electroencephalogr. 1980;11(1):9-15. 
25. Rothenberger A, Blanz B, Lehmkuhl G. What happens to electrical brain activity when anorectic adolescents gain weight? Eur Arch Psychiatry Clin Neurosci. 1991;240(3):144-147.

26. Bradley SJ, Taylor MJ, Rovet JF, et al. Assessment of brain function in adolescent anorexia nervosa before and after weight gain. J Clin Exp Neuropsychol. 1997;19(1):20-33.

27. Grunwald M, Ettrich C, Assmann B, Dähne A, Krause W, Beyer L, et al. Haptic perception and EEG changes in anorexia nervosa. $Z$ Kinder Jugendpsychiatr Psychother. 1999;27(4):241-250.

28. Grunwald M, Ettrich C, Assmann B, et al. Deficits in haptic perception and right parietal theta power changes in patients with anorexia nervosa before and after weight gain. Int J Eat Disord. 2001;29(4): $417-428$.

29. Grunwald M, Weiss T, Assmann B, Ettrich C. Stable asymmetric interhemispheric theta power in patients with anorexia nervosa during haptic perception even after weight gain: a longitudinal study. $J$ Clin Exp Neuropsychol. 2004;26(5):608-620.

30. Hatch A, Madden S, Kohn MR, et al. EEG in adolescent anorexia nervosa: impact of refeeding and weight gain. Int $J$ Eat Disord. 2011;44:65-75.

31. Stunkard AJ, Grace WJ, Wolff HG. The night-eating syndrome: a pattern of food intake among certain obese patients. Am J Med. 1955; 19:78-86.

32. Oswald I, Adam K. Rhythmic raiding of a refrigerator related to rapid eye movement sleep. Br Med J. 1986;292:589.

33. Whyte J, Kavey N. Somnambulistic eating: a report of three cases. Int J Eat Disord. 1990;9:577-581.

34. Schenck CH, Hurwitz TD, Bundlie SR, Mahowald MW. Sleep-related eating disorders: polysomnographic correlates of a heterogeneous syndrome distinct from daytime eating disorders. Sleep. 1991;14(5): 419-431.

35. Spaggiari MC, Granella F, Parrino L, Marchesi C, Melli I, Terzano MG. Nocturnal eating syndrome in adults. Sleep. 1994;17(4):339-344.

36. Vetrugno R, Manconi M, Ferini-Strambi L, Provini F, Plazzi G, Montagna P. Nocturnal eating: sleep-related eating disorder or night eating syndrome? A videopolysomnographic study. Sleep. 2006;29(7): 949-954.

37. Yeh SB, Schenck CH. Sleep-related eating disorder in a 29 year-old man: a case report with disgnostic polysomnographic findings. Acta Neurol Taiwan. 2007;16:106-110.

38. Tóth E, Kondákor I, Túry F, Gáti A, Weisz J, Molnár M. Nonlinear and linear EEG complexity changes caused by gustatory stimuli in anorexia nervosa. Int J Psychophysiol. 2004;51(3):253-260.

39. Tóth E, Túry F, Gáti A, Weisz J, Kondákor I, Molnár M. Effects of sweet and bitter gustatory stimuli in anorexia nervosa on EEG frequency spectra. Int J Psychophysiol. 2004;52(3):285-290.

40. Tammela LI, Pääkkönen A, Karhunen LJ, Karhu J, Uusitupa MI, Kuikka JT. Brain electrical activity during food presentation in obese binge-eating women. Clin Physiol Funct Imaging. 2010;30(2): 135-140.

41. Franken IH, Huijding J, Nijs IM, van Strien JW. Electrophysiology of appetitive taste and appetitive taste conditioning in humans. Biol Psychol. 2011;86(3):273-278.

42. Blechert J, Ansorge U, Beckmann S, Tuschen-Caffier B. The undue influence of shape and weight on self-evaluation in anorexia nervosa, bulimia nervosa and restrained eaters: a combined ERP and behavioral study. Psychol Med. 2011;41(1):185-194.

43. Kucharska-Pietura K, Nikolaou V, Masiak M, Treasure J. The recognition of emotion in the faces and voice of anorexia nervosa. Int $J$ Eat Disord. 2004;35(1):42-47.

44. Zonnevijlle-Bender MJ, van Goozen SH, Cohen-Kettenis PT, van Elburg A, van Engeland H. Do adolescent anorexia nervosa patients have deficits in emotional functioning? Eur Child Adolesc Psychiatry. 2002;11(1):38-42.

45. Dodin V, Nandrino IL. Cognitive processing of anorexic patients in recognition tasks: an event-related potentials study. Int J Eat Disord. 2003;33:299-307.
46. Gramann K, Toellner T, Krummenacher J, Eimer M, Muller HJ. Brain electrical correlates of dimensional weighting: an ERP study. Psychophysiology. 2007;44:277-292.

47. Nittono H, Shibuya Y, Hori T. Anterior N2 predicts subsequent viewing time and interest rating for novel drawings. Psychophysiology. 2007;44:687-696

48. Kiefer M, Marzinzik F, Weisbrod M, Scherg M, Spitzer M. The time course of brain activations during response inhibition: evidence from event-related potentials in a go/no go task. Neuroreport. 1998;9: $765-770$.

49. Polich J, Kok A. Cognitive and biological determinants of P300: an integrative review. Biol Psychol. 1995;41:103-146.

50. Pollatos O, Herbert BM, Schandry R, Gramann K. Impaired central processing of emotional faces in anorexia nervosa. Psychosom Med. 2008;70(6):701-708.

51. Hatch A, Madden S, Kohn MR, et al. Emotion brain alterations in anorexia nervosa: a candidate biological marker and implications for treatment. J Psychiatry Neurosci. 2010;35(4):267-274.

52. Babiloni C, Del Percio C, De Rosas M, et al. Attentional cortical responses to enlarged faces are related to body fat in normal weight subjects: an electroencephalographic study. Clin Neurophysiol. 2009;120(5):922-931.

53. Babiloni C, Del Percio C, Triggiani AI, et al. Attention cortical responses to enlarged faces are reduced in underweight subjects: an electroencephalographic study. Clin Neurophysiol. 2011;122(7): $1348-1359$.

54. Squires NK, Squires KC, Hillyard SA. Two varieties of long-latency positive waves evoked by unpredictable auditory stimuli in man. Electroencephalogr Clin Neurophysiol. 1975;38(4):387-401.

55. Torigoe K, Numata O, Sato T, et al. Contingent negative variation in children with anorexia nervosa. Pediatr Int. 1999;41(3):285-291.

56. Rau JH, Struve FA, Green RS. Electroencephalographic correlates of compulsive eating. Clin Electroencephalogr. 1979;10(4): 180-189.

57. Balakireva EE, Kozlova IA, Iakupova LP, Savost'ianova OL. Typology of disordered eating behaviour (anorexia nervosa with bulimia and vomitomanic disturbances) in children and adolescents. Zh Nevrol Psikhiatr Im S S Korsakova. 2004;104(7):15-21.

58. Silva JR, Pizzagalli DA, Larson CL, Jackson DC, Davidson RJ. Frontal brain asymmetry in restrained eaters. $J$ Abnorm Psychol. 2002;111(4):676-681.

59. Hynek K, Faltus F. An EEG study in anorexia nervosa and an attempt to use it for prognostic prediction. Cesk Psychiatr. 1990;86(6): 369-374.

60. Schenck CH, Hurwitz TD, O'Connor KA, Mahowald MW. Additional categories of sleep-related eating disorders and the current status of treatment. Sleep. 1993;16(5):457-466.

61. Robinson S, Young RE, Golden MH. Electrophysiological assessment of brain function in severe malnutrition. Acta Paediatr. 1995;84: $1245-1251$

62. Holliday J, Tchanturia K, Landau S, Collier D, Treasure J. Is impaired set-shifting an endophenotype of anorexia nervosa? Am J Psychiatry. 2005; $162: 2269-2275$.

63. Tchanturia K, Morris RG, Anderluh MB, Collier DA, Nikolaou V, Treasure J. Set shifting in anorexia nervosa: an examination before and after weight gain, in full recovery and relationship to childhood and adult OCPD traits. $J$ Psychiatr Res. 2004;38:545-552.

64. Jáuregui-Lobera I. Neuroimaging in eating disorders. Neuropsychiatr Dis Treat. 2011;7:577-584.

65. Kilts CD, Egan G, Gideon DA, Ely TD, Hoffman JM. Dissociable neural pathways are involved in the recognition of emotion in static and dynamic facial expressions. Neuroimage. 2003;18:156-168.

66. Kaye W. Neurobiology of anorexia and bulimia nervosa. Physiol Behav. 2008;94(1):121-135.

67. Kaye WH, Bulik CM, Thornton L, Barbarich N, Masters K. Comorbidity of anxiety disorders with anorexia and bulimia nervosa. Am J Psychiatry. 2004;161:2215-2221. 
68. Holtkamp K, Muller B, Heussen N, Remschmidt H, Herpertz-Dahlmann B. Depression, anxiety, and obsessionality in longterm recovered patients with adolescent-onset anorexia nervosa. Eur Child Adolesc Psychiatry. 2005;14:106-110.
69. Tiggeman M, Kemps E. The phenomenology of food cravings: the role of mental imagery. Appetite. 2005;45:305-313.

\section{Publish your work in this journal}

Neuropsychiatric Disease and Treatment is an international, peerreviewed journal of clinical therapeutics and pharmacology focusing on concise rapid reporting of clinical or pre-clinical studies on a range of neuropsychiatric and neurological disorders. This journa is indexed on PubMed Central, the 'PsycINFO' database and CAS.
The manuscript management system is completely online and includes a very quick and fair peer-review system, which is all easy to use. Visit http://www.dovepress.com/testimonials.php to read real quotes from published authors.

Submit your manuscript here: http://www.dovepress.com/neuropsychiatric-disease-and-treatment-journal 